\title{
Reliability Verification and Practical Effectiveness Evaluation of the Nursing Administration Analysis Formulae Based on PSYCHOMS ${ }^{\circledR}$
}

\author{
Misao Miyagawa1, Kaori Katou'2, Yuko Yasuhara3 ${ }^{3}$, Kazuyuki Matsumoto", \\ Motoyuki Suzuki' ${ }^{\text {, Takako Takebayashi6, Tetsuya Tanioka }}{ }^{3}$, Rozzano Locsin ${ }^{3}$ \\ ${ }^{1}$ Department of Nursing, Faculty of Health and Welfare, Tokushima Bunri University, Tokushima, Japan \\ ${ }^{2}$ The Major in Nursing School of Health Sciences, The University of Tokushima, Tokushima, Japan \\ ${ }^{3}$ Institute of Health Biosciences, The University of Tokushima Graduate School, Tokushima, Japan \\ ${ }^{4}$ Faculty of Engineering, The University of Tokushima, Tokushima, Japan \\ ${ }^{5}$ Faculty of information Science and Technology, Osaka Institute of Technology, Osaka, Japan \\ ${ }^{6}$ Umibenomori Hospital, Kochi, Japan \\ Email: miyagawa@tks.bunri-u.ac.jp, c201103063@tokushima-u.ac.jp, yasuhara@medsci.tokushima-u.ac.jp, \\ matumoto@is.tokushima-u.ac.jp, moto@m.ieice.org, ttakebayashi@umibeno-mori.com, \\ tanioka.tetsuya@tokushima-u.ac.jp, locsin@medsci.tokushima-u.ac.jp
}

Received 7 October 2014; revised 23 November 2014; accepted 10 December 2014

Copyright (C) 2014 by authors and Scientific Research Publishing Inc.

This work is licensed under the Creative Commons Attribution International License (CC BY). http://creativecommons.org/licenses/by/4.0/

(c) (i) Open Access

\begin{abstract}
In psychiatric hospitals, the ratios between patients versus physician and patients versus nurse are low as compared to those in general hospitals. Furthermore, usages of electronic medical records are also low so that nurse administrators are limited in their ability to compile, analyze, and generate patient care staffing information for their administrative use. Psychiatric nurse administrators anticipate the development of a nursing administration analysis system that could perform personnel data simulation, manage information on nursing staff, and manage ward/ practice operations. Responding to this situation, the authors developed a nursing administration analysis system utilizing formulae from the Psychiatric Outcome Management System, PSYCHOMS ${ }^{\circledR}$ to aid nurse administrators. Such formulae are awaiting patent approval. The purpose of this study was to examine the validity of the formulae and the Structured Query Language (SQL) statement, and its practical effectiveness of analyzing data. The study findings showed that two kinds of computation expressions - a classification and extraction were able to display required information desired by nurse administrators. Moreover, significant information critical to assigning staff was validated to ensure high quality of nursing care according to the function and characteristic of the hospital ward.
\end{abstract}


Keywords

Analysis Formulae, Nursing Administration Analysis, Psychiatric Hospital, PSYCHOMS ${ }^{\circledR}$

\section{Introduction}

Efforts have been extensive in improving the quality of care and hospitalization of psychiatric patients particularly in their treatment, and the quality of care available community mental health and social welfare services [1]-[4]. It is known that Japanese psychiatric hospitals are overcrowded, involving long patient hospitalization stays, thereby increasing their likelihood of having complicating diseases because of aging.

As a vision of the reform for mental health welfare of 2004, psychiatric and mental health treatments towards community care of the mentally ill were promoted instead of continuing inpatient psychiatric hospitalization [5]. In order to improve the quality of life of psychiatric patients through accurate and appropriate mental health services, nurse administrators must be able to determine how to provide high-quality nursing care and integrated rehabilitation which are most effective and efficient [6]-[8]. However, in psychiatric hospitals, there are few physicians and nurses as compared to the general hospital. Patient and physician ratio is 48 patients to one physician, while patients and nurse ratio is 15 patients to one nurse. However, in general hospitals in Japan, the average ratio of patients to physician is 16 patients to one physician, and 7 patients to one nurse [9].

In addition, the problem of long-stay hospitalization is still a pressing issue in Japan [10] [11]. Therefore, as the supporting system for providing maximum efficiency of medical services using limited human and material resources, the Psychiatric Outcome Management System (PSYCHOMS ${ }^{\circledR}$ registered trademark) was developed guided by perspectives from a nursing standpoint.

Analyzing the current situation in psychiatric hospitals, forming strategies and using these in actual nursing practice are keys for achieving and maintaining high-quality human health care [12] [13], thereby supporting the critical nature of nurse administrators' work of analyzing information/data. While the scope of nursing administration has expanded in recent years, and the information required for nursing administration has increased dramatically in both volume and diversity [14], the clinical site has also changed radically with each daily practice. Nursing administrators are asked to make timely and informed decisions according to data derived from situations founded on increasing evidences which are exact and central to the undertaking at hand.

However, nurse administrators are limited in their ability to compile and analyze information for nursing administration. Nurse administrators in psychiatric wards would greatly benefit from the development of a nursing administration analysis system that could perform personnel arrangement simulation, manage information on nursing staff and ward operations [15]. PSYCHOMS ${ }^{\circledR}$ can allow nurse administrators to make these appropriate and critical decisions.

Within the PSYCHOMS ${ }^{\circledR}$, the nursing administration analysis formula was developed to benefit nurse administrators [16]. This is currently under consideration for patent approval [17]. The purpose of this study was to examine the validity of the formulae and the Structured Query Language (SQL) statement, and its practical effectiveness of analyzing data.

\section{Methods}

\subsection{Setting of the Study}

Information on the psychiatric hospital "A" for analysis: the specialties of psychiatric hospital "A" where analytical information was acquired include the Department of Psychiatry and Psychosomatic Medicine. In-patient wards are for psychiatric acute ward ( 1 ward, 60 beds), psychiatric chronic wards ( 3 wards, 180 beds), neurological diseases treatment ward ( 1 ward, 60 beds), and dementia treatment ward ( 1 ward, 55 beds).

\subsection{Analysis Formulae}

This analysis formula [16] [17] uses two different approaches: 1) data are classified into types of information as desired by the nursing administrator, 2) extracted data required by the nursing administrator. This formula can be classified information registered in the database based upon categories (S_category) and conditions 
(S_condition) established by the user, from which the information is extracted that correspond to the condition. Analysis formulae are indicated below:

$$
\begin{gathered}
\inf (x)=\sum_{i=1}^{m} S_{-} \text {category }(i \mid x) \boldsymbol{\square} \sum_{j=1}^{m} S_{-} \text {condition }(j \mid x) \\
\inf 2(x)=E F(1) \boldsymbol{\square} \sum_{j=1}^{m} S_{-} \text {condition }(j \mid x) \\
\inf 3(x)=E F(2) \boldsymbol{\square} \sum_{j=1}^{m} S_{-} \text {condition }(j \mid x) \\
\inf n(x)=E F(n-1) \boldsymbol{\square} \sum_{j=1}^{m} S_{-} \text {condition }(j \mid x)
\end{gathered}
$$

$\inf ($ ): analytical (classification/extraction) information;

$x$ : the selected condition;

$i$ : the factor meeting the condition;

$j$ : the factor meeting the condition $x$;

$m$ : the total number (record);

S_category: the selected category;

S_condition: the selected condition;

$E F(1)$ : the first analytical result;

$E F(2)$ : the second analytical result;

$E F(n-1)$ : the $n-1$ st analytical result.

In addition, the operator “ $\square$ ” in formulae (1)-(4) represents the extraction of overlapping parts of records in the former and latter parts and on the right side of the equation. To view classified data, when there are multiple categories and/or conditions, records matching each category and condition must all be extracted from the data tables of the database.

\subsection{Methods of Verification Test}

1) To build the database, using the data for nursing administration of the hospital "A".

2) To output data from the created database, using SQL search statements, being based on the following analysis framework (Figure 1).

3) To evaluate quantitatively the output data of the practical effectiveness using the nursing administration analysis formulae, from the viewpoint of psychiatric nurse administrators.

There were eight evaluators: 2 nurse administrators, 3 nursing administration researchers, and 3 persons experienced in software programming. The period was from August 2014 to October 2014.

\begin{tabular}{|c|c|c|c|}
\hline \multirow{2}{*}{ Analytical results } & \multicolumn{3}{|c|}{ Analytical process } \\
\hline & formula (1) & formula (2) & formula (3) \\
\hline $\begin{array}{l}\text { Analysis } 1 \text { : Collation of } \\
\text { nursing staff assignment in } \\
\text { psychiatric chronic wards and } \\
\text { staff nurses' competence levels }\end{array}$ & $\begin{array}{l}\text { The classification of career } \\
\text { ladder levels in psychiatric } \\
\text { chronic wards }\end{array}$ & $\begin{array}{l}\text { The extraction of staff names } \\
\text { in which evaluation result } \\
\text { differs by self and by a head } \\
\text { nurse }\end{array}$ & $\begin{array}{l}\text { The extraction of each } \\
\text { staff's years of clinical } \\
\text { experience }\end{array}$ \\
\hline $\begin{array}{l}\text { Analysis 2: Collation of } \\
\text { preceptor nurse's ladder level } \\
\text { and his or her skill }\end{array}$ & $\begin{array}{l}\text { The extraction of preceptor } \\
\text { nurse's in all wards of the A } \\
\text { hospital }\end{array}$ & $\begin{array}{l}\text { The extraction of the } \\
\text { preceptor nurse's career } \\
\text { ladder level }\end{array}$ & $\begin{array}{l}\text { Extraction of achievement } \\
\text { toward the career ladder } \\
\text { level }\end{array}$ \\
\hline
\end{tabular}

\subsection{Ethical Considerations}

Ethical consideration for this study was assured by obtaining permission to conduct this study from the Clinical Research and Ethical Review Board of Tokushima University (receipt number: 1501-1).

Figure 1. Analysis framework: analytical process and estimated results. 


\section{Results}

\subsection{Analysis 1: Collation of Nursing Staff Assignment in Psychiatric Chronic Wards and Staff Nurses' Competence Levels}

Step 1: Display the number of nursing stuff applicable to a career ladder level of each psychiatric chronic ward (Table 1).

Formula

$$
\inf (x)=\sum_{i=1}^{m} S_{-} \text {category }(i \mid x) \boldsymbol{\square} \sum_{j=1}^{m} S_{-} \text {condition }(j \mid x)
$$

\section{SQL statement}

SELECT: ward_function, hospital_ward, career_ladder_level_by_self, career_ladder_level_by_a_head_nurse, $\operatorname{COUNT}(*)$

FROM: nursing_staff_administration_database

WHERE: ward_function = 'psychiatric_chronic_wards'

GROUP BY: ward_function, hospital_ward, career_ladder_level_by_self, career_ladder_level_by_a_head_ nurse

Step 2: Display the nursing staff name which shows the career ladder level by self and by a head nurse. The difference can be seen in the classified result of Step 1 (Table 2).

\section{Formula}

$$
\inf 2(x)=E F(1) \boldsymbol{\square} \sum_{j=1}^{m} S_{-} \text {condition }(j \mid x)
$$

Data table (1) is a table holding all the records of the staff applicable to inf ( $x$ ).

\section{SQL statement}

SELECT: ward_function, hospital_ward, nursing_staff_name, career_ladder_level_by_self, career_ladder_ level_by_a_head_nurse

FROM: data_table (1)

WHERE: career_ladder_level_by_self $<>$ career_ladder_level_by_a_head_nurse

Step 3: Display the applicable staff's years of clinical experience is displayed from the extracted result of Step 2 (Table 3).

\section{Formula}

$$
\inf 3(x)=E F(2) \square \sum_{j=1}^{m} S_{-} \text {condition }(j \mid x)
$$

Data table (2) is a table holding all the records of the staff applicable to inf $2(x)$.

\section{SQL statement}

SELECT: ward_function, hospital_ward, nursing_staff_name, staff's_years_of_clinical_experience FROM: data table (2)

WHERE: staff's_years_of_clinical_experience

\subsection{Evaluation of the Analysis Result 1}

The competency of staff assigned to 3 psychiatric chronic wards was classified according to their career ladder levels. Then the staff names and their years of clinical experience with a difference of their career ladder by self and by a head nurse, were extracted. This result can be useful as an evaluation indicator in order to quantitatively/ qualitatively provide staff assignment according to the characteristic of the wards. 
Table 1. Classified results of the collation of nursing staff assignment and stuff nurses' competence levels in each psychiatric chronic ward.

\begin{tabular}{|c|c|c|c|c|c|c|c|}
\hline \multirow[b]{2}{*}{ Ward function } & \multirow{2}{*}{$\begin{array}{c}\text { Hospital ward } \\
\text { name }\end{array}$} & \multicolumn{3}{|c|}{ Career ladder level by self } & \multicolumn{3}{|c|}{ Career ladder level by a head nurse } \\
\hline & & $\begin{array}{c}\text { Career ladder } \\
\text { level I }\end{array}$ & $\begin{array}{l}\text { Career ladder } \\
\text { level } \Pi\end{array}$ & $\begin{array}{c}\text { Career ladder } \\
\text { level Ш-1 }\end{array}$ & $\begin{array}{c}\text { Career ladder } \\
\text { level I }\end{array}$ & $\begin{array}{l}\text { Career ladder } \\
\text { level } \Pi\end{array}$ & $\begin{array}{c}\text { Career ladder } \\
\text { level Ш-1 }\end{array}$ \\
\hline \multirow{3}{*}{$\begin{array}{c}\text { Psychiatric } \\
\text { chronic wards }\end{array}$} & Ward 1 & 2 & 5 & 3 & 2 & 5 & 3 \\
\hline & Ward 5 & 3 & 7 & 1 & 3 & 3 & 5 \\
\hline & Ward 6 & 2 & 5 & 4 & 2 & 6 & 3 \\
\hline
\end{tabular}

The number shows the number of nurses in the career ladder level.

Table 2. The extracted results of the nursing staff name which career level by self and by a head nurse differ in classified result of Step 1.

\begin{tabular}{|c|c|c|c|}
\hline Ward function & Hospital ward name & $\begin{array}{c}\text { Career ladder level by self }<\text { Career ladder } \\
\text { level by a head nurse }\end{array}$ & $\begin{array}{c}\text { Career ladder level by self }>\text { Career ladder } \\
\text { level by a head nurse }\end{array}$ \\
\hline \multirow{2}{*}{$\begin{array}{l}\text { Psychiatric chronic } \\
\text { wards }\end{array}$} & Ward 5 & $\begin{array}{l}\text { nurse A nurse B } \\
\text { nurse C nurse D }\end{array}$ & \\
\hline & Ward 6 & & nurse $\mathrm{E}$ \\
\hline
\end{tabular}

Table 3. The extracted results of the applicable staff's years of clinical experience is displayed from the extracted result of Step 2.

\begin{tabular}{|c|c|c|c|}
\hline Ward function & Hospital ward name & $\begin{array}{c}\text { Career ladder level by self }<\text { Career ladder } \\
\text { level by a head nurse }\end{array}$ & $\begin{array}{c}\text { Career ladder level by self }>\text { Career ladder } \\
\text { level by a head nurse }\end{array}$ \\
\hline \multirow[t]{2}{*}{$\begin{array}{l}\text { Psychiatric chronic } \\
\text { wards }\end{array}$} & Ward 5 & $\begin{array}{c}\text { nurse A (10 years) } \\
\text { nurse B (16 years) } \\
\text { nurse C (18 years) } \\
\text { nurse D (8 years) }\end{array}$ & \\
\hline & Ward 6 & & nurse E (7 years) \\
\hline
\end{tabular}

\subsection{Analysis 2: Collation of Preceptor Nurse's Ladder Level and His or Her Skill}

Step 1: Display the extraction of preceptor nurse's name in all wards of the A hospital (Table 4).

\section{Formula}

$$
\inf (x)=\sum_{i=1}^{m} S_{-} \text {category }(i \mid x) \boldsymbol{\square} \sum_{j=1}^{m} S_{-} \text {condition }(j \mid x)
$$

\section{SQL statement}

SELECT: hospital_ward, nursing_staff_name

FROM: nursing_staff_administration_database

WHERE: role = "preceptor"

Step 2: Display the preceptor nurse’s career ladder level from the result of Step 1 (Table 5).

\section{Formula}

$$
\inf 2(x)=E F(1) \boldsymbol{\square} \sum_{j=1}^{m} S_{-} \text {condition }(j \mid x)
$$

Data table (1) is a table holding all the records of the staff applicable to inf ( $x$ ).

\section{SQL statement}

SELECT: hospital_ward, nursing_staff_name, preceptor_nurse's_career_ladder_level

FROM: data_table (1) 
Step 3: Extracted result of the achievement situation toward the career ladder level from the result of Step 2 (Table 6).

Formula

$$
\inf 3(x)=E F(2) \square \sum_{j=1}^{m} S_{-} \text {condition }(j \mid x)
$$

Data table (2) is a table holding all the records of the staff applicable to inf 2 (x).

\section{SQL statement}

SELECT: hospital_ward, nursing_staff_name, career_ladder_level_by_a_head_nurse, achievement_situation_ toward_the_career_ladder_level

FROM: data_table (2)

\subsection{Evaluation of the Analysis Result 2}

By having extracted the data of the preceptor nurse, it was shown clearly that the preceptor nurse was not assigned in all the wards, and was found that all preceptor nurses did not achieve the career ladder level Ш-1. These information serves as data for work on the policy not only based on the education for novice nurse but also the education of the nurse who plays a role of their leader level, or one who offers high quality nursing care.

Table 4. The extracted result of preceptor nurse's name in all wards of the A hospital.

\begin{tabular}{cc} 
Hospital ward name & Preceptor \\
\hline Ward 1 & nurse F \\
Ward 3 & nurse G \\
Ward 5 & nurse H, nurse I \\
Ward 6 & nurse J, nurse K \\
\hline
\end{tabular}

Table 5. The extracted result of the preceptor nurse's career ladder level.

\begin{tabular}{ccc}
\hline Hospital ward name & Preceptor nurse & Career ladder level \\
Ward 1 & nurse F & $\Pi$ \\
Ward 3 & nurse G & nurse H \\
Ward 5 & nurse I & $\Pi$ \\
& nurse J & $\Pi$ \\
Ward 6 & nurse K & Ш-1 \\
\hline
\end{tabular}

Table 6. The extracted result of achievement toward the career ladder level.

\begin{tabular}{|c|c|c|c|c|}
\hline Hospital ward name & $\begin{array}{c}\text { Number of } \\
\text { preceptor nurse }\end{array}$ & $\begin{array}{c}\text { Name of } \\
\text { preceptor nurse }\end{array}$ & Career ladder position & $\begin{array}{l}\text { Achievement situation toward } \\
\text { the career ladder level }\end{array}$ \\
\hline Ward 1 & 1 & nurse F & $\Pi$ & unachieved \\
\hline Ward 3 & 1 & nurse G & $\Pi$ & unachieved \\
\hline \multirow{2}{*}{ Ward 5} & \multirow{2}{*}{2} & nurse $\mathrm{H}$ & $\Pi$ & unachieved \\
\hline & & nurse I & Ш-1 & unachieved \\
\hline \multirow{2}{*}{ Ward 6} & \multirow{2}{*}{2} & nurse $\mathrm{J}$ & $\Pi$ & unachieved \\
\hline & & nurse $\mathrm{K}$ & III-1 & unachieved \\
\hline
\end{tabular}

The number shows an applicable nurse's number. 


\section{Discussion}

The contents of care required in psychiatric hospitals differ in accordance with the function of each respective ward [18]-[21]. Therefore, in order to provide appropriate service to patients, a nursing administrator must make efforts to organize information concerning the degree of busyness and the abilities of nursing staff as well as to correctly understand the characteristics and appropriate placement of nursing staff in each ward. The reuse of stored data will give a powerful tool for management of nursing schedule and lead to improvement of hospital services [22] [23]. However, the information that the nursing administrator requires is not only an aggregation of quantitative data, coefficient of correlation or analytical results of the difference between the averages, but also any method assembling this information should also extract and show what information is included in outliers.

As shown in Analysis 1, the nursing administrator requires, from the results of quantitative analysis, information concerning in whose cases the career ladder level placement by one's own assessment is different from that by the chief nurse, and where the difference between one's self-assessment and the assessments by others lies. Analytical results were divided into whether career ladder levels in the chief nurse's assessment are higher or lower than those in the self-assessment of nursing staff. These results are shown in the screen display of a computer, which shows that necessary information was successfully obtained.

In Analysis 2, the practical abilities of nurses playing the role of preceptor are extracted. In hospital "A", the nurses who attain career ladder level Ш-1 are qualified as preceptors. However, from the results of Analysis 2, all six preceptor nurses did not achieve the items required in ladder level III- 1 and did not fulfill the necessary requirements. In previous studies, research showed the improvement of nursing outcomes with data mining using the data saved in the database of the hospital [22] [23].

What nursing administrators require is a method of objective assessment of the abilities of staff and information useful in deriving what ongoing education is necessary for the improvement of the quality of nursing [24] [25]. Also, when nurses are educated about performance and quality measures, are engaged in identifying outcomes and collecting meaningful data, are active participants in disseminating quality reports, and are able to recognize the value of these activities, data become one with practice [26].

Because information is quantitatively handled in statistical processing, it is difficult for the nursing administrator at the nursing site to calculate necessary information by combining qualitative and quantitative information. As a result of analysis based on the developed calculation formula, it was possible to show necessary information by mixing both calculation methods of analysis and extraction as well as by combining quantitative and qualitative data. Nursing administrators who really understand the necessity of information analysis input various data into spreadsheet software. However, they lack a comprehension of what can be read out from the input data. Or they cannot make full use of the analytical method, so that the actual situation is that the vast amounts of information collected often cannot be used [27] [28].

The system is developed by focusing on support for the idea of nursing administration analysis. For example, in order to analyze the actual condition of a ward, it is necessary to make analyses, from various perspectives, such as "what happens to ' $\mathrm{B}$ ' under the conditions of 'A'? and what happens to ' $\mathrm{C}$ '?” For this purpose, it is required to rearrange and filter the data using spreadsheet software in each case. In the calculation formula that Miyagawa et al. [16] proposed, the nursing administrator can classify data and extract necessary information by intuitively combining the data of "A" and "B" on a screen display. The nursing administrator, even if he/she is unfamiliar with statistical processing, can obtain the information necessary for combination from the information input in the database.

There are some competent nursing administrators acquired the degree of master of business administration or the $\mathrm{PhD}$ in nursing, having capability of information analysis or statistical analysis. Moreover, nursing informatics is established as one of the fields of nursing science, and this specialist offer information that nursing administrator's needs. However, in Japan, there is little such in the present condition [29]. Therefore, we developed the methodology which can do analysis intuitively, even if the nurse administrator is not well versed in information analysis. It was thought that this methodology is effective in order to support a nursing administration's decision-making.

The major limitation of the study is evaluated results in the one hospital. It is necessary to perform subsequent experimental study on several hospitals, and to improve developed formulae in order to use by an electronic nursing system. 


\section{Conclusion}

Information required for nursing administration was able to be analyzed and displayed according to the need of each nurse administrator. Especially, it has verified that information important for the nursing staff assignment for assuring the quality of nursing care according to a ward function or the characteristic was acquired.

\section{Acknowledgements}

We would like to express our deep gratitude to the participants of this study, our family members, and members of Professor Dr. Tanioka’s laboratory. In particular, we wish to thank the Prof. Dr. Fuji Ren, and the nurse administrators who cooperated this study. Also, this study was supported by a grant from the Strategic Information and Communication R \& D Promotion Program (SCOPE) in Japan (No. 122309008).

\section{References}

[1] Ikebuchi, E., Satoh, S. and Anzai, N. (2008) What Impedes Discharge Support for Persons with Schizophrenia in Psychiatric Hospitals? Seishin Shinkeigaku Zasshi, 110, 1007-1022. (In Japanese)

[2] Ryu, Y., Mizuno, M., Sakuma, K., Munakata, S., Takebayashi, T., Murakami, M., et al. (2006) Deinstitutionalization of Long-Stay Patients with Schizophrenia: The 2-Year Social and Clinical Outcome of a Comprehensive Intervention Program in Japan. Australian and New Zealand Journal of Psychiatry, 40, 462-470. http://dx.doi.org/10.1080/j.1440-1614.2006.01823.x

[3] Hansson, L. and Markström, U. (2014) The Effectiveness of an Anti-Stigma Intervention in a Basic Police Officer Training Programme: A Controlled Study. BMC Psychiatry, 25, 14-55.

[4] Kunitoh, N. (2013) From Hospital to the Community: The Influence of Deinstitutionalization on Discharges Long-Stay Psychiatric Patients. Psychiatry and Clinical Neurosciences, 67, 384-396. http://dx.doi.org/10.1111/pcn.12071

[5] Shift from Hospitalized Medical Treatment to Living in the Community "Visions in Reform of Mental Health and Medical Welfare”. http://ncnp.go.jp/nimh/keikaku/vision/index_e.html

[6] Tanioka, T., Kataoka, M., Yasuhara, Y., Miyagawa, M. and Ueta, I. (2011) The Role of Nurse Administrators and Managers in Quality Psychiatric Care. Journal of Medical Investigation, 58, 1-10. http://dx.doi.org/10.2152/jmi.58.1

[7] Tanioka, T., Chiba, S., Onishi, Y., Kataoka, M., Kawamura, A., Tomotake, M., et al. (2013) Factors Associated with Discharge of Long-Term Inpatients with Schizophrenia in Japan: A Retrospective Study. Issues in Mental Health Nursing, 34, 256-264. http://dx.doi.org/10.3109/01612840.2012.742602

[8] Pitkänen, A., Hätönen, H., Kuosmanen, L. and Välimäki, M. (2008) Patients’ Descriptions of Nursing Interventions Supporting Quality of Life in Acute Psychiatric Wards: A Qualitative Study. International Journal of Nursing Studies, 45, 1598-1606. http://dx.doi.org/10.1016/j.ijnurstu.2008.03.003

[9] Ministry of Health, Labor and Welfare, Japan, Handout. http://www.mhlw.go.jo/stf/shingi/2r985200000264pratt/2r985200000264x9.pdf (In Japanese)

[10] Oshima, I., Mino, Y. and Inomata, Y. (2007) How Many Long-Stay Schizophrenia Patients Can Be Discharged in Japan? Psychiatry and Clinical Neuroscience, 61, 71-77. http://dx.doi.org/10.1111/j.1440-1819.2007.01613.x

[11] Bartusch, S.M., Elgeti, H., Bastiaan, P., Macheidt, W. and Ziegenbein, M. (2006) Hannover Study on Long-Stay Hospitalization-Part I: Prediction of Long-Stay Hospitalization in Cases of Chronic Mental Illness. Clinical Practice \& Epidemiology in Mental Health, 22, 2-10.

[12] Callaly, T. and Arya, D. (2005) Organizational Change Management in Mental Health. Australasian Psychiatry, 13, 120-123.

[13] Shur, R. and Simons, N. (2008) Quality Issues in Health Care Research and Practice. Nursing Economics, 26, $258-262$.

[14] Taguchi, M. and Tsuruta, K. (2009) Study of Data Items Used by Nurse Administrators in Operating Facilities. Japanese Red Cross College of Nursing Bulletin, 23, 27-35. (In Japanese)

[15] Miyagawa, M., Yasuhara, Y., Tanioka, T. and Locsin, R. (2013) Clarification of a Demand Function Required for a Staff Assignments Support Program for Nursing Administrator Use in Psychiatric Hospitals. Information, 17, 361-366.

[16] Miyagawa, M., Tanioka, T., Yasuhara, Y., Matsumoto, K., Ito, H., Suzuki, M., et al. (2014) Methodology for Developing a Nursing Administration Analysis System. Intelligent Information Management, 6, 118-128. http://dx.doi.org/10.4236/iim

[17] Tanioka, T., Yasuhara (Sakama), Y., Miyagawa, M. and Itou, H. (2014) Analysis Program for the Nursing Administration and the Variance of the Clinical Pathways. Patent-Pending in Japan, Japan Patent No. 2014-20227711.

[18] Fukao, K., Hinoki, S., Inoue, T. and Sawa, A. (2006) Function of Emergency Wards of the Hospital in Comprehensive 
Psychiatric Care. Seishin Shinkeigaku Zassi, 108, 1074-1078. (In Japanese)

[19] Takahashi, A. (2010) Clinical Phase-Oriented Organization of Psychiatric Hospital. Journal of Japanese Association of Psychiatric Hospital, 29, 390-392. (In Japanese)

[20] Yada, H., Omori, H., Funakoshi, Y. and Katoh, T. (2010) Current State of Research on Occupational Stress of Psychiatric Nurses and Insight into Its Future. Journal of UOEH, 32, 265-272. (In Japanese)

[21] Haraguchi, M. and Kawamura, S. (2006) The Features of Nursing Judgment on Differences of Patient's Conditions: Comparison between Chronic Patient's Model and Acute Patient's Model. The Journal of Japan Academy of Health Sciences, 9, 120-128. (In Japanese)

[22] Iwata, H., Tsumoto, S. and Hirano, S. (2013) Clinical Schedule Management Using Similarity-Based Mining Methods. Proceedings of the 2013 IEEE International Conference on Healthcare Informatics (ICHI), Philadelphia, 9-11 September 2013, 396-405. http://dx.doi.org/10.1109/ICHI.2013.55

[23] Cadmus, E., Van Wynen, E.A., Chamberlain, B., Steingall, P., Kilgallen, M.E., Holly, C., et al. (2008) Nurses’ Skill Level and Access to Evidence-Based Practice. Journal of Nursing Administration, 38, 494-503. http://dx.doi.org/10.1097/01.NNA.000033947.42596.18

[24] Randolph, P.K., Hinton, J.E., Hagler, D., Mays, M.Z., Kastenbaum, B., Brooks, R., et al. (2012) Measuring Competence: Collaboration for Safety. The Journal of Continuing Education in Nursing, 43, 548-549. http://dx.doi.org/10.3928/00220124-20121120-79

[25] Chan, S.W., Chien, W.T. and Tso, S. (2009) Evaluating Nurses’ Knowledge, Attitude and Competency after an Education Programme on Suicide Prevention. Nurse Education Today, 29, 763-769. http://dx.doi.org/10.1016/j.nedt.2009.03.013

[26] Albanese, M.P., Evans, D.A., Schantz, C.A., Bowen, M., Disbot, M., Moffa, J.S., et al. (2010) Engaging Clinical Nurses in Quality and Performance Improvement Activities. Nursing Administration Quarterly, 34, 226-245. http://dx.doi.org/10.1097/NAQ.0b013e318e702ca

[27] Hedelin, L. and Allwood, A.M. (2002) IT and Strategic Decision Making. Industrial Management \& Data Systems, 102, 125-139. http://dx.doi.org/10.1108/02635570210421318

[28] Effken, J.A., Brewer, E.B., Brewer, M.D., Logue, M.D., Gephart, S.M. and Verran, J.A. (2011) Using Cognitive Work Analysis to Fit Decision Support Tools to Nurse Managers' Work Flow. CIN: Computers, Informatics, Nursing, 20, 245-250. http://dx.doi.org/10.1097/NCN.0b013e318f9dcfa

[29] Ota, K. (1998) About Nursing Information Science. Quality Nursing, 4, 163-169. (In Japanese) 
Scientific Research Publishing (SCIRP) is one of the largest Open Access journal publishers. It is currently publishing more than 200 open access, online, peer-reviewed journals covering a wide range of academic disciplines. SCIRP serves the worldwide academic communities and contributes to the progress and application of science with its publication.

Other selected journals from SCIRP are listed as below. Submit your manuscript to us via either submit@scirp.org or Online Submission Portal.
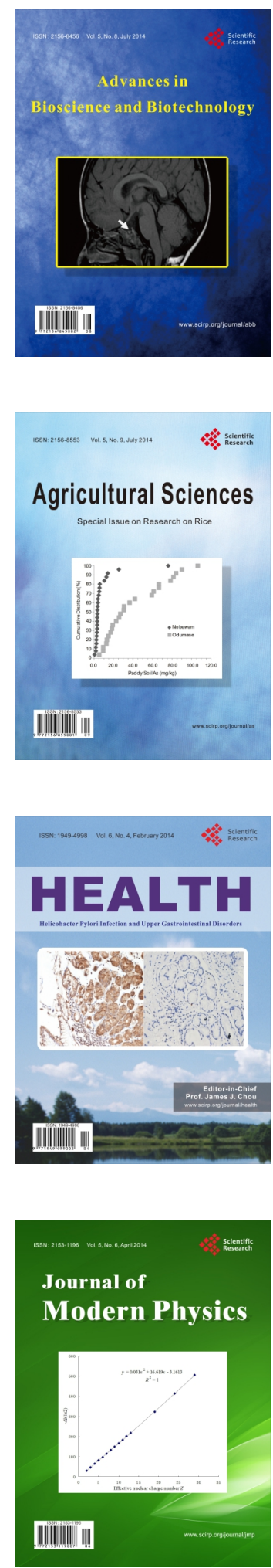
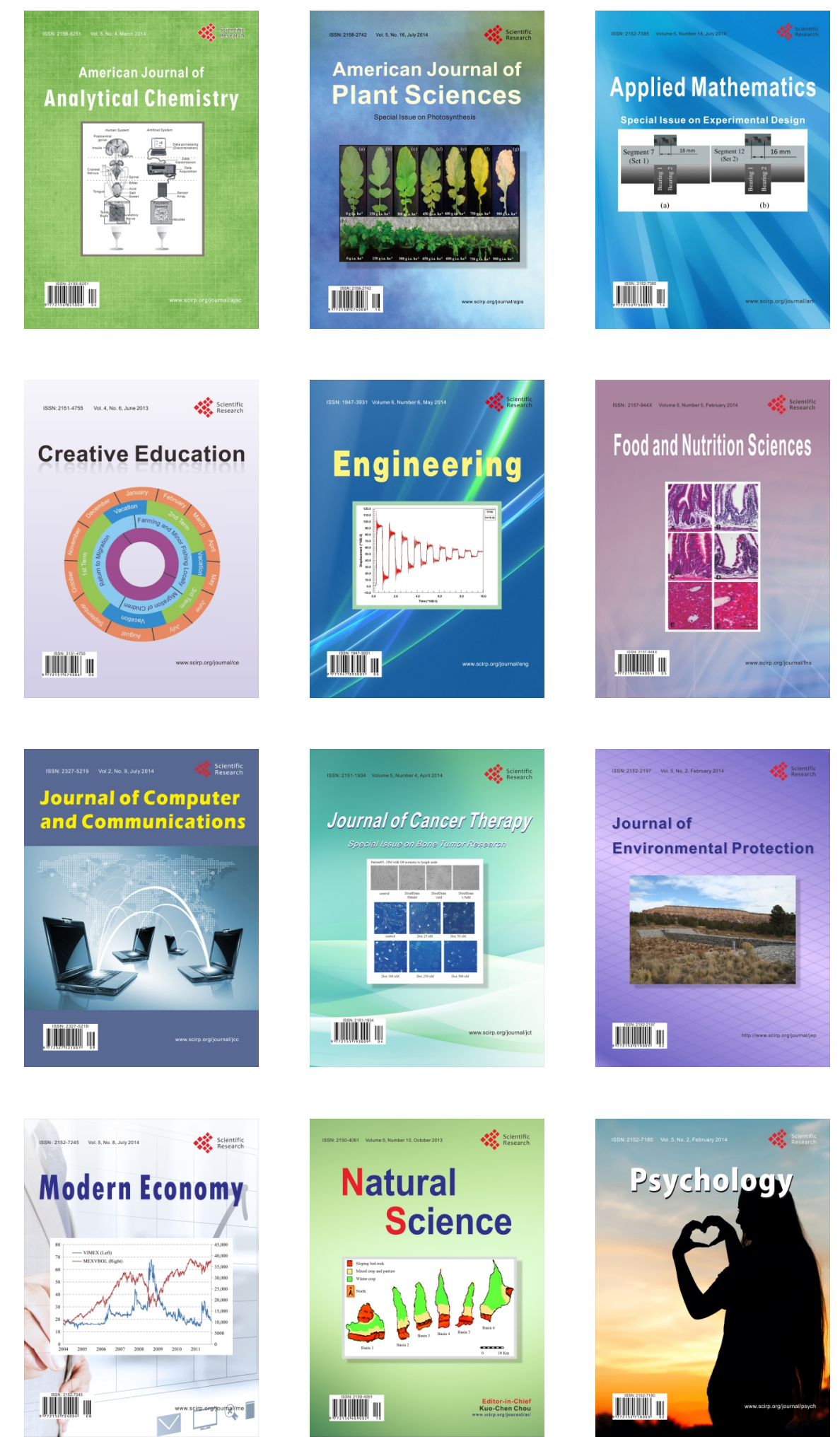